\title{
A Comparative Analysis by Experimental Investigations on Normal and Ground Ultrafine Mineral Admixtures in Arresting Permeation in High-Strength Concrete
}

\author{
B. Karthikeyan $(\mathbb{D}),{ }^{1}$ Senthil Kumaran Selvaraj $\left(\mathbb{D},{ }^{2}\right.$ G. Dhinakaran, ${ }^{1}$ G. Sundaramali $\left(\mathbb{D},{ }^{2}\right.$ \\ Natarajan Muthuswamy, ${ }^{3}$ and Velmurugan Paramasivam (iD) ${ }^{4}$ \\ ${ }^{1}$ School of Civil Engineering, SASTRA Deemed to be University, Thanjavur 613401, Tamilnadu, India \\ ${ }^{2}$ Department of Manufacturing Engineering, School of Mechanical Engineering (SMEC), Vellore Institute of Technology (VIT), \\ Vellore 632014, Tamilnadu, India \\ ${ }^{3}$ Department of Thermal and Energy Engineering, School of Mechanical Engineering (SMEC), \\ Vellore Institute of Technology (VIT), Vellore 632014, Tamilnadu, India \\ ${ }^{4}$ School of Mechanical and Automotive Engineering, College of Engineering and Technology, Dilla University, \\ P.O. Box 419, Dilla, Ethiopia
}

Correspondence should be addressed to Senthil Kumaran Selvaraj; senthilkumaran.s@vit.ac.in and Velmurugan Paramasivam; drvelmuruganp@du.edu.et

Received 10 November 2021; Revised 27 December 2021; Accepted 18 January 2022; Published 2 February 2022

Academic Editor: Wenjie Ge

Copyright ( 92022 B. Karthikeyan et al. This is an open access article distributed under the Creative Commons Attribution License, which permits unrestricted use, distribution, and reproduction in any medium, provided the original work is properly cited.

\begin{abstract}
This paper discusses the permeation characteristics of concrete made by increasing the fineness of the conventional mineral admixtures and using them as a partial substitute for cement. Silica fume and metakaolin ground to ultrafine state and ceramic powder obtained from grinding waste ceramic tiles were used as mineral admixtures. The mixes were designed for a compressive strength of $50 \mathrm{MPa}$ and were prepared for both binary and ternary blended cases. Binary blended specimens were cast, partially replacing cement with unground silica fume, ground silica fume, unground metakaolin, and ground metakaolin separately in different replacement proportions. Ternary blended mixes were prepared using ceramic powder in $4 \%, 9 \%$, and $14 \%$ and with silica fume in a constant level of $1 \%$ percentage. All the cast specimens were compared against the control concrete. A deeper comparative analysis was also made by comparing the performance of specimens made with unground mineral admixtures with that of ground mineral admixtures. Various parameters such as resistance against water absorption, percentage of voids, and sorptivity characteristics were studied. It was observed that increasing the fineness helps fill up the pores, thereby improving the resistance to permeation action.
\end{abstract}

\section{Introduction}

The pore structure of concrete is considered one of the significant characteristics of concrete as it plays a vital role in assessing the mechanical and durability properties of concrete [1]. Pore structure, in general, includes pores of all types such as air voids, capillary pores, and gel pores. The presence of pores in concrete causes permeation of fluid particles into the concrete and, if permitted for a more extended period, may threaten the stability of the structures. Permeability of concrete is arrived at by measuring the flow of any fluid, mainly water, under pressure gradient [2] Resistance to permeation is an essential property in highperformance concrete. It plays a significant role in estimating the performance of the concrete as it affects the durability of the structures, especially those exposed to aggressive environments. The presence of pores in concrete leads to the permeation of water, salt, and other natural agents, resulting finally in the deterioration of concrete. This can be controlled by incorporating more refined supplementary cementitious materials available as industrial byproducts. Silica fume and metakaolin are the commonly 
used supplementary cementitious materials among those possessing pozzolanic nature.

Many reports are available in justifying the capability of such supplementary cementitious materials in resisting permeability and improveing performance. Poon et al. [3] reported that comparing the concrete with silica fume and metakaolin, the metakaolin-based concrete resulted in dense matrix possessing low porosity characteristics.

In addition to the industrial by-products used as supplementary cementitious materials, a few authors have used industrial dumped wastes such as both in cement and fine aggregate to enhance the durability characteristics of concrete. Karthikeyan and Dhinakaran [4] have carried out works with construction waste ceramic powder and reported that strength development was better in 15\% replacement of ceramic powder for cement, and it was mentioned that the improvement in strength is mainly due to the pore-filling effect. Karthikeyan et al. [5] developed a high=strength concrete using dumped iron ore tailings as fine aggregate and reported that the iron ore tailings can be used up to a maximum replacement level of $30 \%$ for fine aggregate, and the authors also mentioned that waste utilization in concrete with suitable adaptation of fibres can yield better strength and durability.

Adding to the earlier research works of using conventional mineral admixtures in a typical form, many research works were completed and many are still in progress with nanosized mineral admixtures in making a densely packed concrete structure to arrest the permeation, and a few are presented in this section. Jo et al. [6] in their experimental research stated that mixing nano- $\mathrm{SiO}_{2}$ to cement improved the early age and 28-day strength of the cement mortars due to the increased surface area, thereby increasing the rate of pozzolanic reaction which ultimately led to an increase in strength. Pacheco-Torgal et al. [7] developed high-performance concrete with nanoparticles, and their report discussed the use of nanoparticles in concrete and their benefits, and also, it suggested suitable methods to improve the mechanical properties of high-performance concrete. Actually, Ali et al. [8-10] contributed more to the research on using nanosized mineral admixtures such as $\mathrm{ZnO}_{2}$ and $\mathrm{TiO}_{2}$ in regular as well as self-compacting concrete.

Though the use of nanosized mineral admixture provided a densely packed concrete matrix, thereby reducing the permeation characteristics, the cost involved is too high, so the ultrafine mineral admixtures were tried by many researchers to make the concrete economically feasible and durable, and few of them are discussed here. Karthikeyan and Dhinakaran $[11,12]$ developed a high-strength concrete by blending ultrafine $\mathrm{TiO}_{2}$ with silica fume and presented its behavior in both fiber-reinforced and -unreinforced concrete specimens. Karthikeyan and Dhinakaran $[13,14]$ tried using the conventional mineral admixtures in their ultrafine state. They found that there was undoubtedly an improvement in the mechanical and durability properties when the size of the conventional supplementary cementitious mineral admixtures reduced to an ultrafine state. Chai et al. [15] carried out works with ground fly ash to prepare highstrength concrete. Felekoğlu et al. [16] performed experimental investigations by grinding coarse fly ash and optimizing the fineness to attain a high strength. Teng et al. [17] used ultrafine ground granulated blast furnace slag to improve high-strength concrete's mechanical and durability properties.

Although, the discussed literature presents a clear view about the contribution of ultrafine mineral admixtures in offering better strength properties, other durability properties such as permeation, presence of voids, and their effects on the pore structure of the concrete need proper experimental validation. It is essential to check whether durability properties such as the strength and performance of concrete made with ultrafine mineral admixtures depend on pore presence, size, and distribution in the concrete. The total volume of pores present in a mix affects the strength and elasticity of concrete [18]. Niu et al. [19] discussed the porefilling capability of superfine slag in cement paste. It is reported that the use of superfine slag decreased the presence of voids and resulted in better porosity behavior and more overdue to their complete hydration, and the strength of mortars increased. This paper presents the experimental investigations adopted in studying the durability characteristics of concrete made with ultrafine mineral admixtures and the effect due to size reduction in filling up the pores.

In the present study, the permeation characteristics of specimens made with normal silica fume and metakaolin were compared with those of specimens made with ultrafine silica fume and ultrafine metakaolin. The ultrafine state was obtained by grinding the commonly available silica fume and metakaolin using a ball mill. The main focus of this study is to assess the capability of ground silica fume and ground metakaolin in resisting the permeability and porosity properties. A permeability test was conducted through the sorptivity method. Based on the sorptivity, porosity, and water absorption test results, the replacement levels required for attaining durability and the comparison in the permeation resisting characteristics of ground and unground specimens were discussed. In addition to ground/unground silica fume, ground/unground metakaolin, to implement waste utilization specimens using ceramic powder, was also made, and the results were also discussed.

1.1. Research Scope and Significance. This paper reports the permeation characteristics of high-strength concrete with ultrafine mineral admixtures. Though many works were reported in strengthening the pore structure using nanosized and ultrafine cementitious materials, limited works were carried out on silica fume due to their finer size and other industrial wastes such as ceramic powder. In this work, the use of the ultrafine mineral admixtures, especially with silica fume, metakaolin, and ceramic powder, and their effect in protecting the pore structure were studied by performing various tests such as sorptivity and porosity tests.

\section{Materials Used}

2.1. Basic Materials. OPC confirming to ASTM C150 [20] was used in the present research. Table 1 presents the composition of cement. River sand possessing physical 
TABle 1: Compounds of cement and other mineral admixtures obtained from XRF.

\begin{tabular}{|c|c|c|c|c|}
\hline \multirow[b]{2}{*}{ Compounds } & \multicolumn{4}{|c|}{ Concentration in percentage } \\
\hline & Cement & $\begin{array}{l}\text { Silica } \\
\text { fume }\end{array}$ & Metakaolin & $\begin{array}{l}\text { Ceramic } \\
\text { powder }\end{array}$ \\
\hline $\mathrm{SiO}_{2}$ & 23 & 97.36 & 53.67 & 55.80 \\
\hline $\mathrm{MgO}$ & 0.4 & 0.79 & 0.09 & 4.28 \\
\hline $\mathrm{Al}_{2} \mathrm{O}_{3}$ & 0.6 & 0.53 & 43.34 & 19.13 \\
\hline $\mathrm{SO}_{3}$ & 2.5 & 0.51 & 0.27 & 0.54 \\
\hline $\mathrm{Fe}_{2} \mathrm{O}_{3}$ & 4 & 0.15 & 0.46 & 7.88 \\
\hline $\mathrm{CaO}$ & 62 & 0.14 & 0.37 & 7.85 \\
\hline $\mathrm{P}_{2} \mathrm{O}_{5}$ & - & 0.09 & 0.12 & 0.13 \\
\hline $\mathrm{Na}_{2} \mathrm{O}$ & - & 0.06 & 0.12 & 1.17 \\
\hline $\mathrm{Cl}$ & - & 0.02 & 0.02 & 0.13 \\
\hline $\mathrm{K}_{2} \mathrm{O}$ & - & 0.29 & 0.17 & 1.36 \\
\hline $\mathrm{MnO}$ & - & 0.01 & - & 0.04 \\
\hline
\end{tabular}

properties such as fineness modulus 2.60 and a specific gravity of 2.63 was used as fine aggregate. Well-graded coarse aggregate, which was locally available and of standard size greater than $4.75 \mathrm{~mm}$ and less than $12.5 \mathrm{~mm}$ with fineness modulus 2.72 , was used.

2.2. Silica Fume. Silica fume $\left(\mathrm{SiO}_{2}\right)$, a by-product obtained from ferrosilicon industry, was used as one of the mineral admixtures. It is a very fine powder with more than $95 \%$ of the particles having a size less than $1 \mu \mathrm{m}$. The silica fume used in this study was received from Oriental Exporters, Navi Mumbai, Maharashtra, India. Silica fume was used in unground (as supplied) ultrafine states (after grinding in the planetary ball mill). The components of silica fume were found using an XRF analyzer, and Table 1 shows the composition.

2.3. Metakaolin. Metakaolin is derived from purified kaolin clay, formed by calcining purified kaolinite at a temperature range between $650^{\circ} \mathrm{C}$ and $700^{\circ} \mathrm{C}$. Kaolinite is hydrous aluminium silicate and is represented chemically as $\mathrm{Al}_{2} \mathrm{O}_{3} \cdot 2 \mathrm{SiO}_{2} \cdot 2 \mathrm{H}_{2} \mathrm{O}$. Metakaolin is finer than cement particles but coarser than silica fume. Table 1 shows the chemical composition of the metakaolin.

2.4. Ceramic Powder. Industrial by-products such as silica fume, fly ash, and GGBFS are usually pozzolanic and have many chemical components similar to cement. The use of such mineral admixtures in concrete can help in reducing the cement content without affecting the strength characteristics. They indeed help in increasing the long-term strength of concrete. On the other hand, other industrial wastes such as marble, granite, and ceramic powders cannot be expected to exert pozzolanic behavior but can act as inert materials. However, in an excellent powder form, a homogeneous mixture can be arrived at using them. The ceramic powder used in the present work was prepared by grinding waste ceramic tiles in a ball mill. The ceramic powder that is coarser than cement was finely ground to a size much less than that of cement. Though they cannot exert a better pozzolanic characteristic, they can act as fillers in concrete. The specific gravity of ceramic powder is 2.182 . The components of ceramic powder are shown in Table 1.

2.5. Superplasticizer. The superplasticizer CONPLAST SP 430 obtained from FOSROC company was used to induce the workability. It was used in a dosage of 1.5 litres per $100 \mathrm{~kg}$ of cement depending on the required workability.

2.6. Ultrafine Silica Fume and Metakaolin. Silica fume and metakaolin were ground using a planetary ball mill of $320 \mathrm{rpm}$. Zirconium balls of size $10 \mathrm{~mm}$ were used for the grinding process. The balls were added in different time durations, and only 18 balls were used initially. 20 minutes later, the number of balls was increased to 26 . Figure 1 shows the zirconium balls used while grinding metakaolin. The grinding efficiency of the mill is affected by various factors such as the materials to be ground, the ratio of the material to the balls used for grinding, and the grinding ball size. The quantity of the material was judged by trial and error only [25-27]. So, the material silica fume/metakaolin was ground individually for 1 hour in $100 \mathrm{~g}$ and $50 \mathrm{~g}$, and the effect of grinding was observed.

2.7. Ultrafine Ceramic Powder. The ceramic powder was prepared by breaking ceramic tiles into smaller pieces by feeding into a jaw crusher and then grinding waste ceramic tile in a dry ball mill. The ceramic powder was made by grinding waste ceramic tiles in a jaw crusher, making them into less-coarse particles first. Then, the less-coarse particles were fed into a dry ball mill and 7 numbers of $30 \mathrm{~mm}$ diameter steel balls, each weighing $400 \mathrm{~g}$. The grinding process was continued for 30 minutes, 45 minutes, and 60 minutes. A 75-micron sieve was used to collect only the particles that are finer than cement. A particle size analyzer was used to categorize the samples ground for different durations, and the finer samples were used for the research. Figures 2-4 depict the process involved in grinding ceramic tiles. The components were found using $\mathrm{X}$-ray fluorescence $(\mathrm{XRF})$ and are presented in Table 1 to ensure that the ceramic particles also possess chemical properties similar to those of cement and are helpful for a partial replacement for cement.

2.8. Mixture Proportions. The research was conducted for two types of mixes, namely, binary and ternary mix. Among the binary mix category, silica fume, metakaolin, and ceramic powder were used as mineral admixtures as partial substitutes for cement in both unground and ultrafine states. In ternary mix, ceramic powder and silica fume were blended with cement. The mineral admixtures were used to partially replace cement in 5\%,10\%, and $15 \%$. The mixes were proportioned with a water-cement ratio $(w / c)$ of 0.3 . A control mixture without adding supplementary cementitious materials was cast to compare with other mixes. A total of 19 mixes including one control mix, 15 binary mixes (UGSF5, UGSF10, UGSF15, UFSF5, UFSF10, UFSF15, UGMK5, UGMK10, UGMK15, UFMK5, UFMK10, 


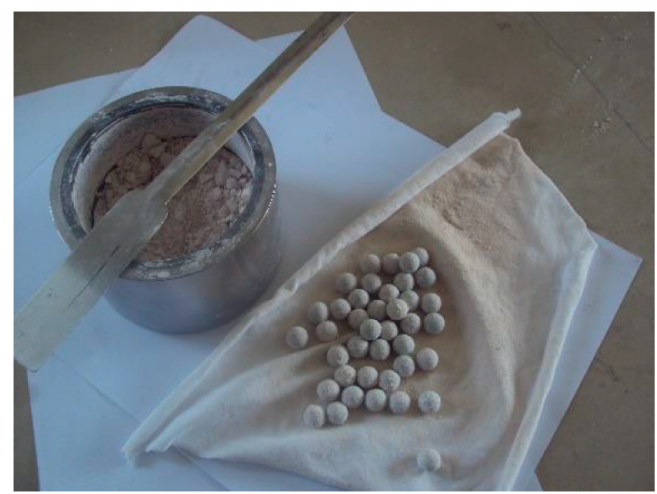

FiguRE 1: Zirconium balls and metakaolin during grinding.

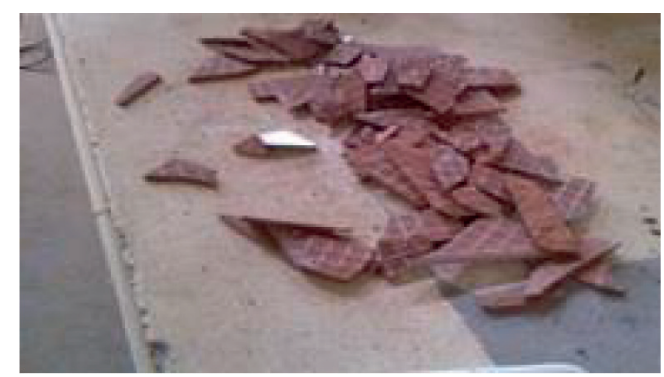

Figure 2: Waste ceramic tiles from construction sites.

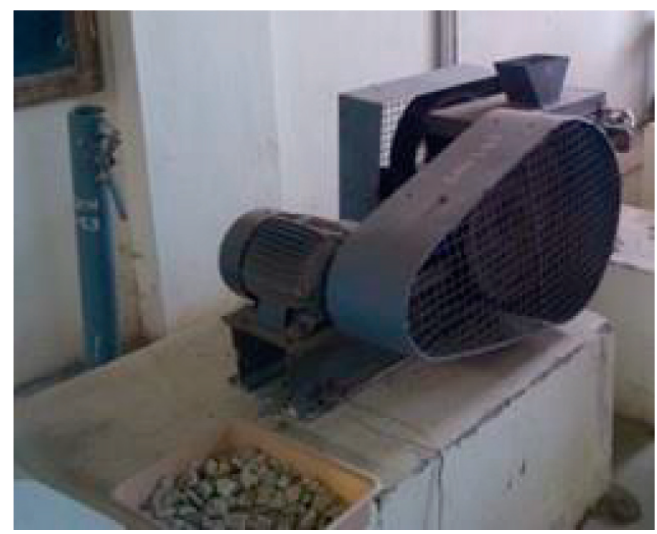

FIGURE 3: Jaw crusher for crushing tiles.

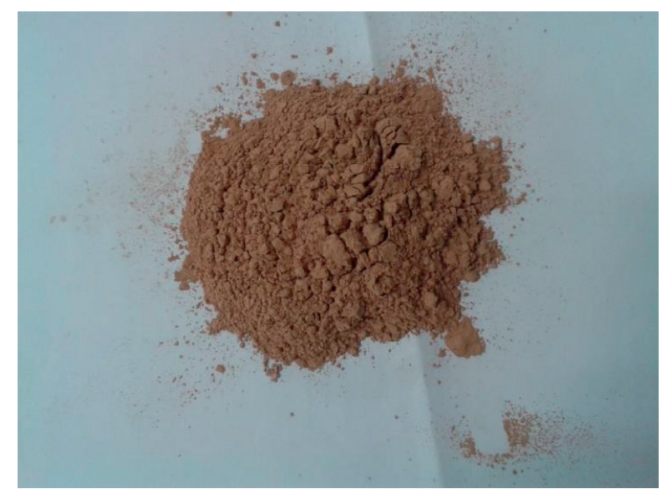

FIGURE 4: Ultrafine ceramic powders after grinding in a planetary ball.
UFMK15, CP5, CP10, and CP15), and 3 ternary mixes (CSF5, CSF10, and CSF15) were made. The main objective of this research work is to check the pore-filling capability due to the increase in the fineness of the mineral admixtures. So, mixes were made using the mineral admixtures in their unground state (UGSF and UGMK) and ground state (GSF and GMK). Ceramic powder (CP) was used in its fine ground state both in binary mixes and ternary mixes. In ternary mixes, the ceramic powder was used in a larger proportion by $4 \%, 9 \%$, and $14 \%$ to encourage waste utilization. Sometimes, ceramic powder may behave like an inert material that can only fill pores and cannot provide necessary pozzolanic action. So, silica fume was added in a minor amount of $1 \%$ to induce pozzolanic action and possess cementitious properties. The mix was named CSF. The mix design was carried out by the ACI method, and the mix proportion obtained was $1: 1.04: 2.13: 0.3$ (cement: fine aggregate: coarse aggregate: w/c) with a suitable addition of superplasticizer. The methodology is illustrated in Figure 5. Tables 2 and 3 show the mix details adopted.

\section{Experimental Investigations}

3.1. Sorptivity. Sorption is the absorption of water under capillary suction. This test will help in assessing the quantum of water absorbed in the pores of the specimen under capillary suction. Cylindrical specimens of size $100 \mathrm{~mm}(d) \times 50 \mathrm{~mm}(h)$ were cast and used for the present work. The specimens after finishing their 28-day period of normal curing were dried in an oven at about $110^{\circ} \mathrm{C}$. Then, the oven-heated specimens were kept in a sealed container to cool them in an ambient temperature. The specimen surfaces were covered with nonporous insulation tape except the bottom surface as shown in Figure 6. Specimens were kept in water only 3 to $5 \mathrm{~mm}$ from the bottom surface to ensure entry of water only through the bottom. The mass of the specimen at the periodical interval was taken in accordance with ASTM C1585 [21]. The volume of water absorbed had been calculated by dividing the total mass of the specimen by the nominal surface area and by the density of water. These obtained values were then plotted against the square root of time, and the water sorptivity coefficient of concrete is the slope of line of the best fit.

3.2. Porosity Test. The durability test for the specimen was conducted by performing a porosity test. The test was performed in accordance with ASTM C642-13 [22]. Cylinder specimens of size $100 \mathrm{~mm}$ (dia) $\times 50 \mathrm{~mm}$ (thick) were cast for various replacement percentages of cement and are kept for 28 days curing. After obtaining the weights of all these specimens at different conditions such as oven-dried weight and saturated weight after keeping in water for 24 hours, as specified in the codal provisions, the percentage of voids (porosity) of the specimen was calculated.

\section{Results and Discussion}

4.1. Size Reduction by Grinding. Ultrafine silica fume and metakaolin were obtained by subjecting the mineral admixtures separately to different hours of grinding in a 


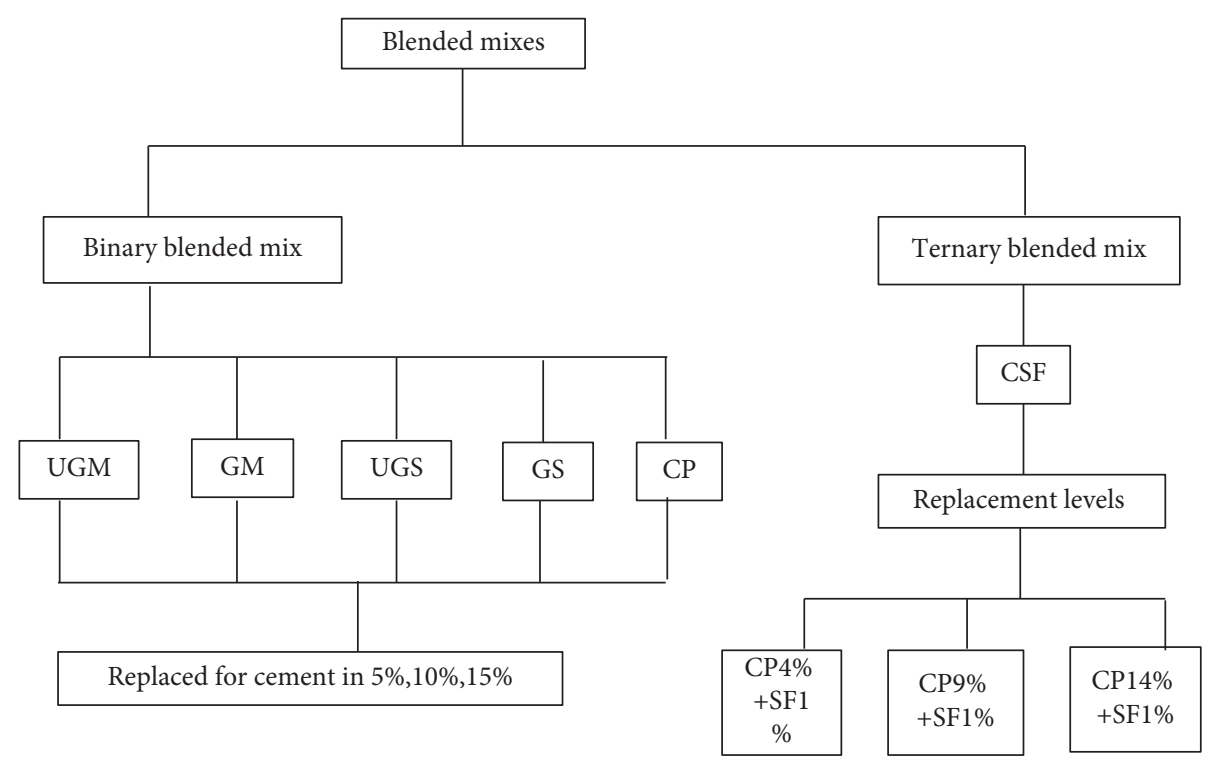

FIGURE 5: Pictorial representation of the mix proportions adopted.

TABle 2: Mix proportion: binary mix (cement and any one mineral admixture).

\begin{tabular}{|c|c|c|c|c|c|c|}
\hline \multirow{2}{*}{ Parameters } & \multicolumn{6}{|c|}{ Mix reference } \\
\hline & Cement $\left(\mathrm{kg} / \mathrm{m}^{3}\right)$ & $\mathrm{SF}\left(\mathrm{kg} / \mathrm{m}^{3}\right)$ & $\mathrm{MK}\left(\mathrm{kg} / \mathrm{m}^{3}\right)$ & $\mathrm{CP}\left(\mathrm{kg} / \mathrm{m}^{3}\right)$ & Fine aggregate $\left(\mathrm{kg} / \mathrm{m}^{3}\right)$ & Coarse aggregate $\left(\mathrm{kg} / \mathrm{m}^{3}\right)$ \\
\hline CONTROL & 522.57 & - & - & - & \multirow{16}{*}{544.18} & \multirow{16}{*}{1113.84} \\
\hline UGSF5 & 496.44 & 26.13 & - & - & & \\
\hline UGSF10 & 470.31 & 52.26 & - & - & & \\
\hline UGSF15 & 444.18 & 78.38 & - & - & & \\
\hline UGMK5 & 496.44 & - & 26.13 & - & & \\
\hline UGMK10 & 470.31 & - & 52.26 & - & & \\
\hline UGMK15 & 444.18 & - & 78.38 & - & & \\
\hline GSF5 & 496.44 & 26.13 & - & - & & \\
\hline GSF10 & 470.31 & 52.26 & - & - & & \\
\hline GSF15 & 444.18 & 78.38 & - & - & & \\
\hline GMK5 & 496.44 & - & 26.13 & - & & \\
\hline GMK10 & 470.31 & - & 52.26 & - & & \\
\hline GMK15 & 444.18 & - & 78.38 & - & & \\
\hline CP5 & 496.44 & - & - & 26.13 & & \\
\hline CP10 & 470.31 & - & - & 52.26 & & \\
\hline CP15 & 444.18 & - & - & 78.38 & & \\
\hline
\end{tabular}

TABLE 3: Mix proportion: ternary (cement $+\mathrm{SF}+\mathrm{CP})$.

\begin{tabular}{lccccc}
\hline \multirow{2}{*}{ Parameters } & \multicolumn{3}{c}{ Mix reference } \\
& Cement $\left(\mathrm{kg} / \mathrm{m}^{3}\right)$ & $\mathrm{CP}\left(\mathrm{kg} / \mathrm{m}^{3}\right)$ & $\mathrm{SF}\left(\mathrm{kg} / \mathrm{m}^{3}\right)$ & Fine aggregate $\left(\mathrm{kg} / \mathrm{m}^{3}\right)$ & Coarse aggregate $\left(\mathrm{kg} / \mathrm{m}^{3}\right)$ \\
\hline CONTROL & 522.57 & - & - & & \\
CSF5 & 496.44 & 25.085 & 1.045 & 544.18 & 1113.84 \\
CSF10 & 470.31 & 50.17 & 2.09 & & \\
CSF15 & 444.18 & 75.24 & 3.14 & & \\
\hline
\end{tabular}

planetary ball mill using zirconium balls. Initially when the ball mill is loaded with its full capacity, the percentage reduction in size was only $20.84 \%$; later, the quantity was reduced to $50 \%$, and a greater percentage of reduction in size about $75.39 \%$ from the original size of microsilica was obtained. Table 4 presents the average diameter size details for which the maximum reduction was obtained. The same procedure was adopted for grinding metakaolin also. It can be seen that major reduction in size of about $75.83 \%$ was obtained when $50 \mathrm{~g}$ of metakaolin was subjected to grinding for 1 hour. The particle size of the ceramic powder checked by using a zeta analyzer and reported as average diameter ensures that their size is less than the size of cement. It is shown in Table 4 and in Figures 7-11. As the particles reached ultrafine size at one hour of grinding, 


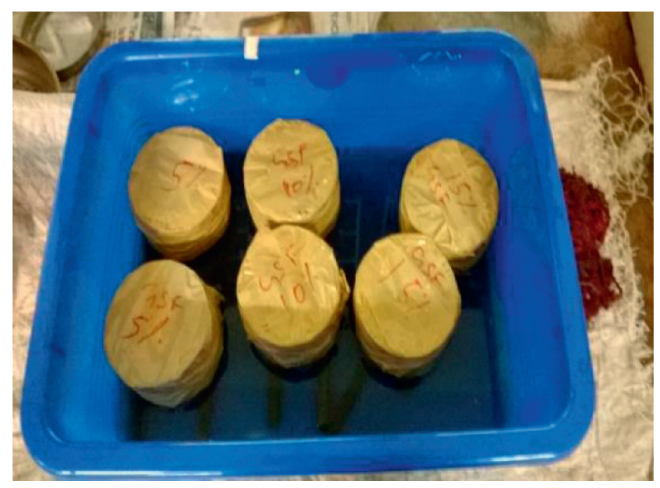

FIGURE 6: Specimens for the sorptivity test.

TABle 4: Reduction in size after grinding.

\begin{tabular}{lcccc}
\hline Sl. no. & Sample type & Duration of grinding (hours) & Size $(\mathrm{nm})$ & Percentage variation in size \\
\hline 1 & UGSF & - & 638 & $75.39 \%$ decrease in size \\
2 & GSF & 1 & 157 & $75.83 \%$ decrease in size \\
\hline 3 & UGMK & - & 1738 & 420 \\
4 & GMK & 1 & 2481 & - \\
\hline 5 & CP & 1 &
\end{tabular}

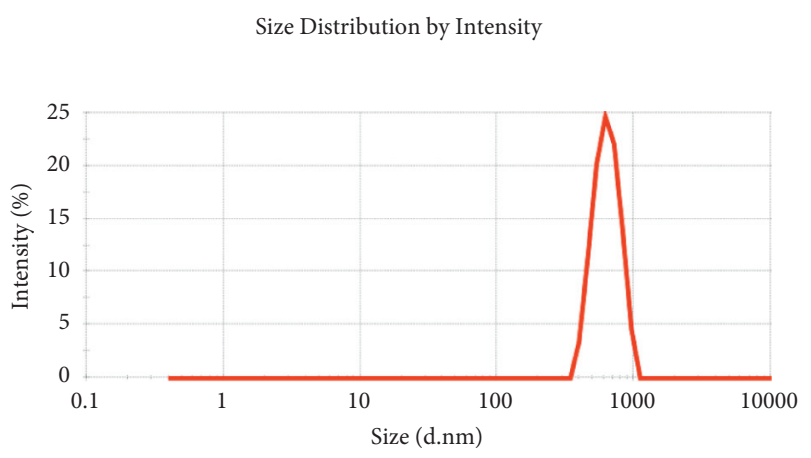

FIGURE 7: Particle size distribution graph of UGSF.

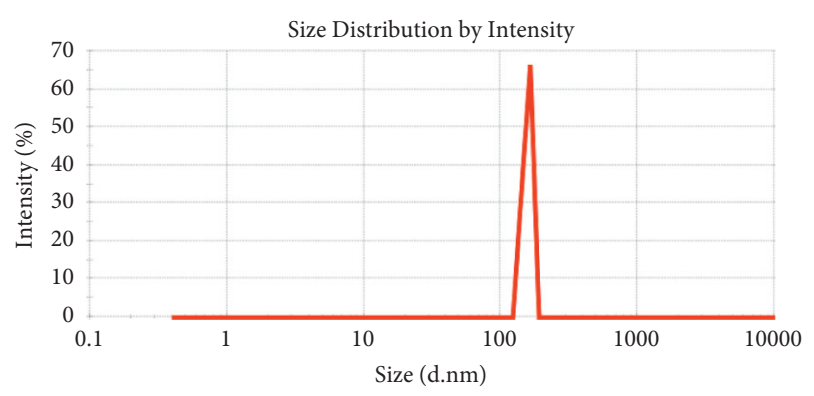

Figure 8: Particle size distribution graph of GSF.

the experiments were carried out with samples ground for one hour only, fixing that as the optimum duration for obtaining finer particles.

4.2. Water Absorption and Sorption Coefficient of SF-Blended Binary Mix. All the SF-mixed specimens showed less water absorption than control by $0.52 \%, 0.54 \%$, and $0.55 \%$ for

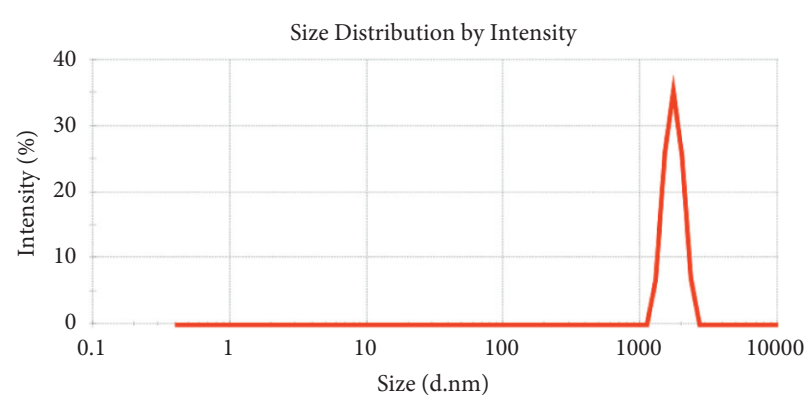

FIgUre 9: Particle size distribution graph of UGMK.

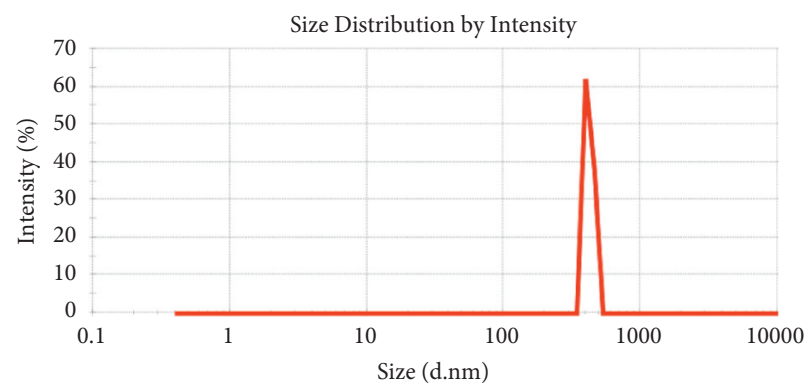

FIgURe 10: Particle size distribution graph of GMK.

UGSF5, UGSF10, and UGSF15 specimens. GSF specimens performed well and have shown better resistance in resisting water permeation showing a much less value than the control and UGSF specimens. The reduction in water absorption is due to the filling of the pores by the ground finesized silica fume which had made the concrete a densely packed one, thus resisting further water absorption. The 


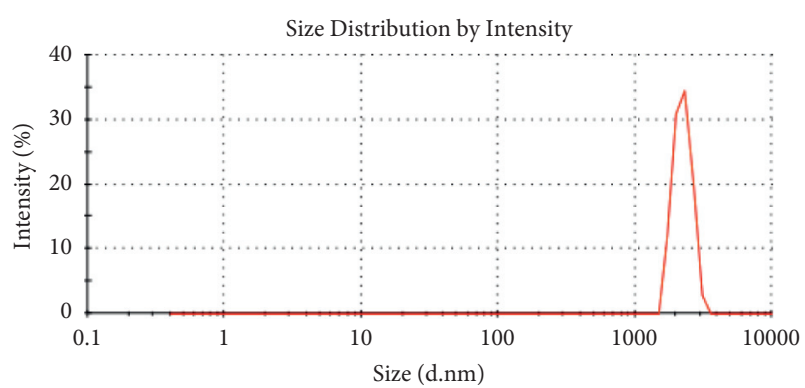

Figure 11: Particle size distribution graph of CP.

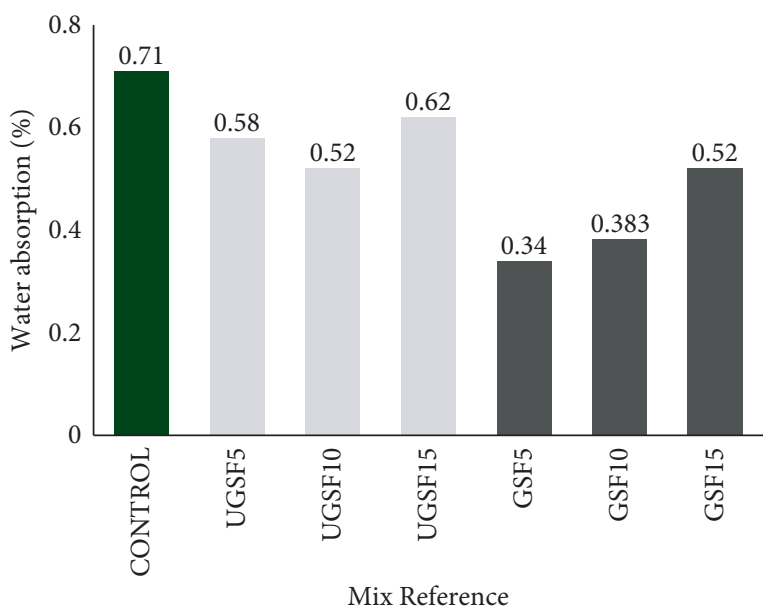

Figure 12: Water absorption values of SF.

TABle 5: Sorption coefficient.

\begin{tabular}{lcccc}
\hline Specimen & \multicolumn{4}{c}{$\begin{array}{c}\text { Replacement levels } \\
\text { Sorption coefficient }\end{array}$} \\
& 0 & 5 & 10 & 15 \\
\hline CONTROL & 0.008 & - & - & - \\
UGSF & - & 0.004 & 0.018 & 0.029 \\
GSF & - & 0.005 & 0.002 & 0.002 \\
UGMK & - & 0.008 & 0.006 & 0.005 \\
GMK & - & 0.008 & 0.007 & 0.009 \\
CP & - & 0.01 & 0.011 & 0.007 \\
CSF & - & 0.241 & 0.141 & 0.074 \\
\hline
\end{tabular}

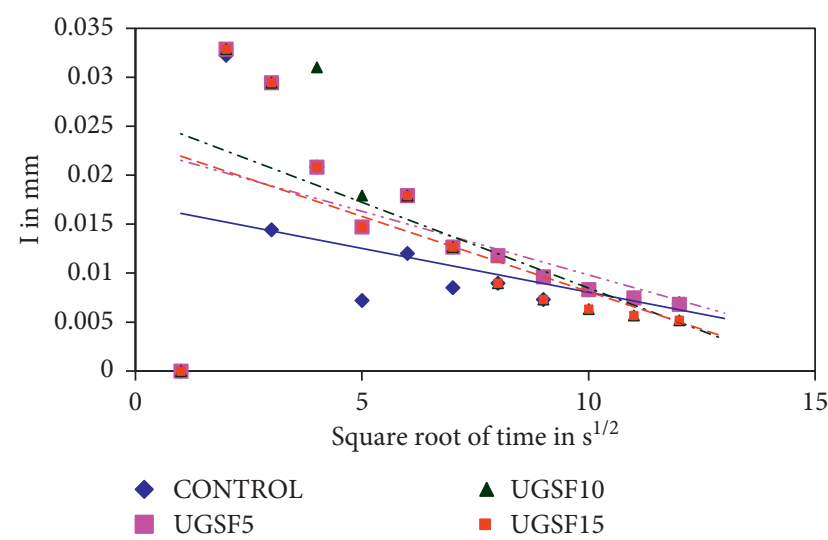

FIGURE 13: Sorption coefficient of UGSF.

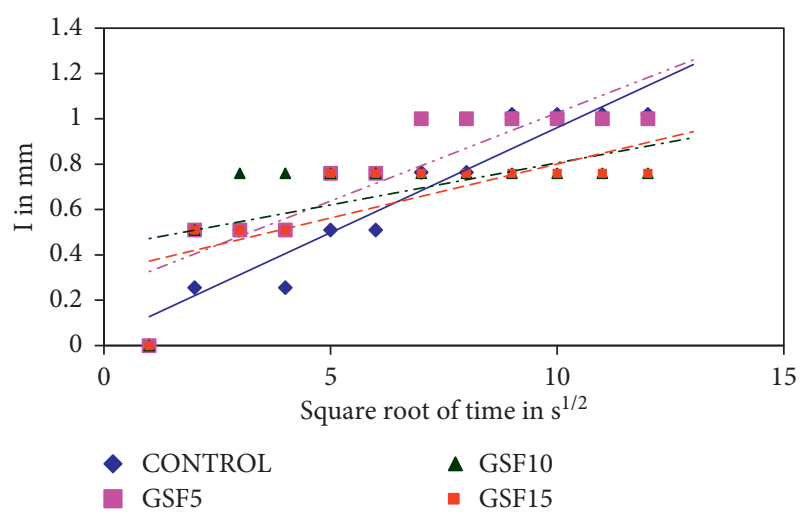

FIGURE 14: Sorption coefficient of GSF.

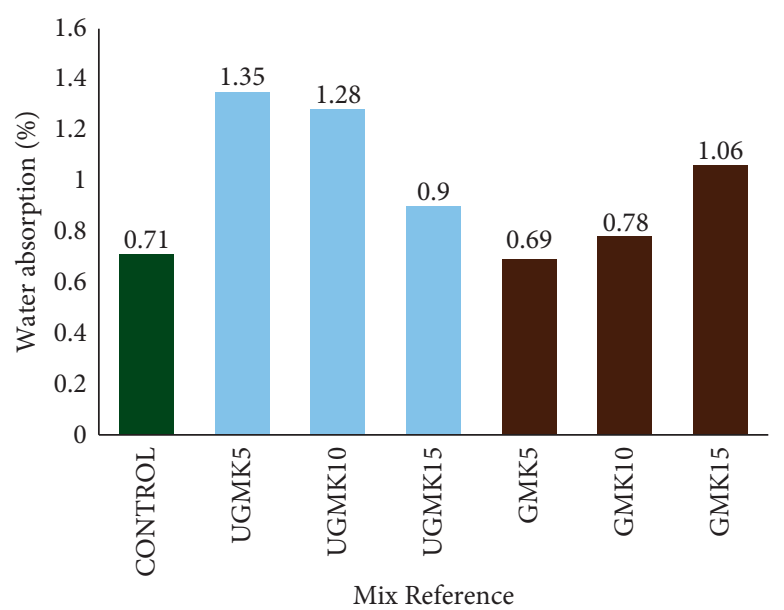

FIgURE 15: Water absorption values of MK.

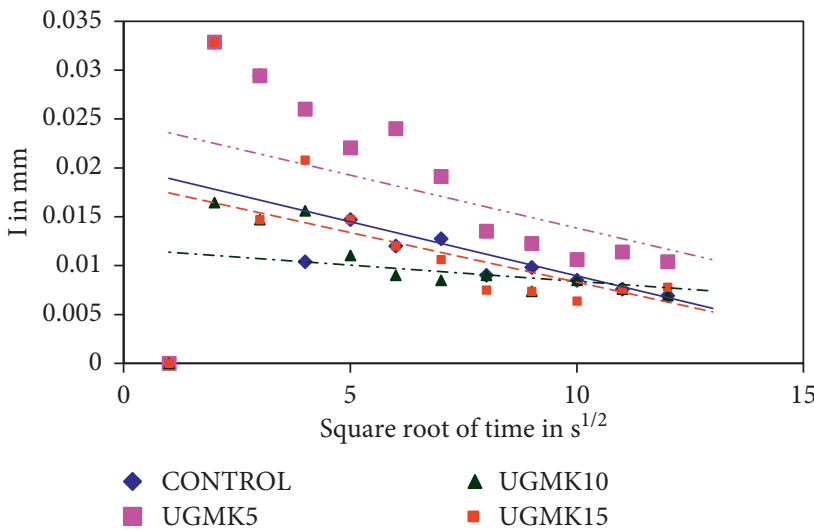

FIGURE 16: Sorption coefficient of UGMK.

effect of ground silica fume GSF in water absorption has already been discussed by the authors in their earlier work [4]; here, it is compared with the UGSF, and it is found that the specimen with GSF performs well in resisting the water absorption. Figure 12 shows the variation in the percentage of water absorption of specimens with SF.

On comparing our results with other research works [23], it was observed that when SF was used as a mineral 


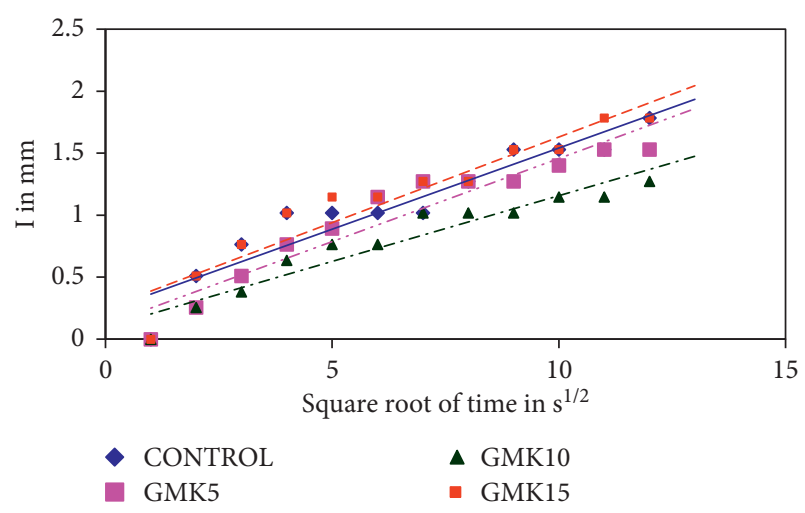

FIGURE 17: Sorption coefficient of GMK.

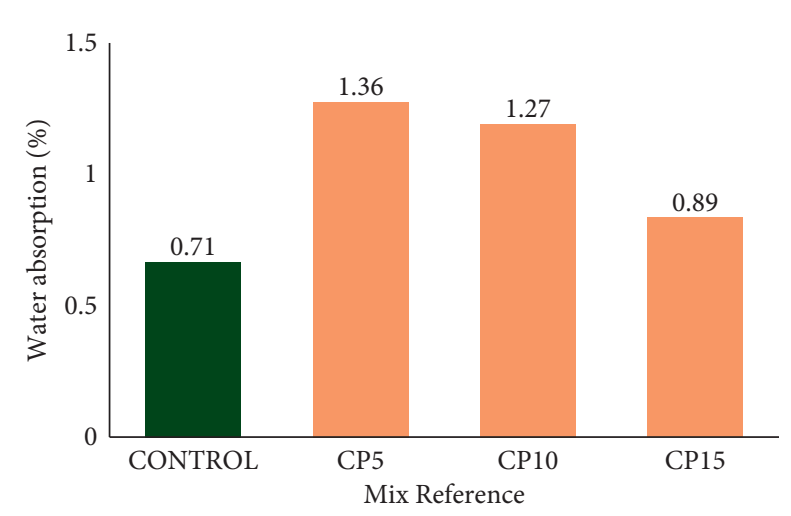

FIGURE 18: Water absorption values of CP.

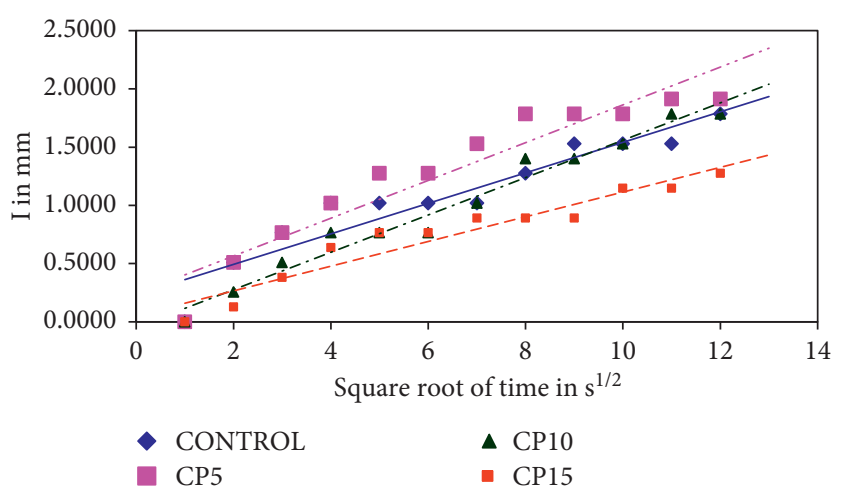

FIgURE 19: Sorption coefficient of CP.

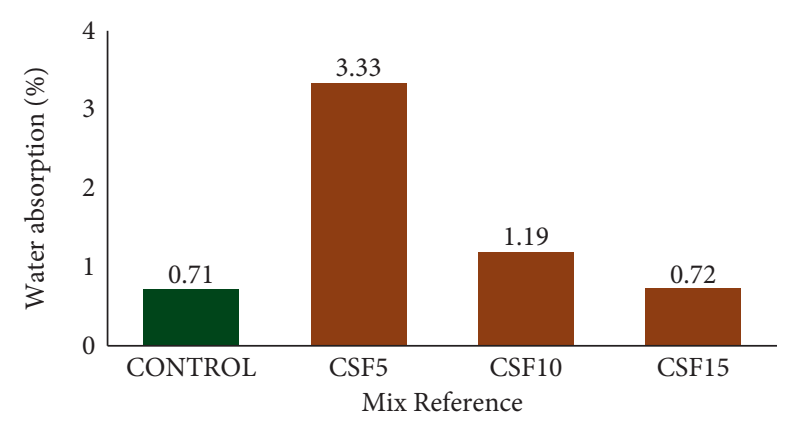

Figure 20: Water absorption values of CSF.

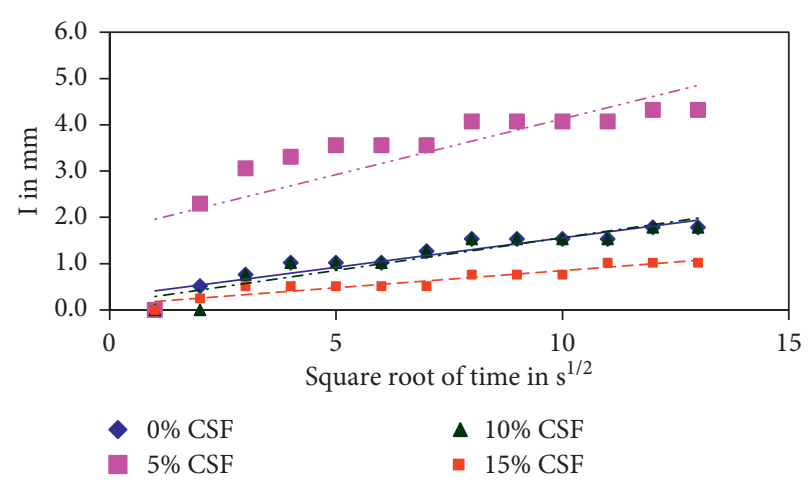

FIgURE 21: Sorption coefficient of CSF.

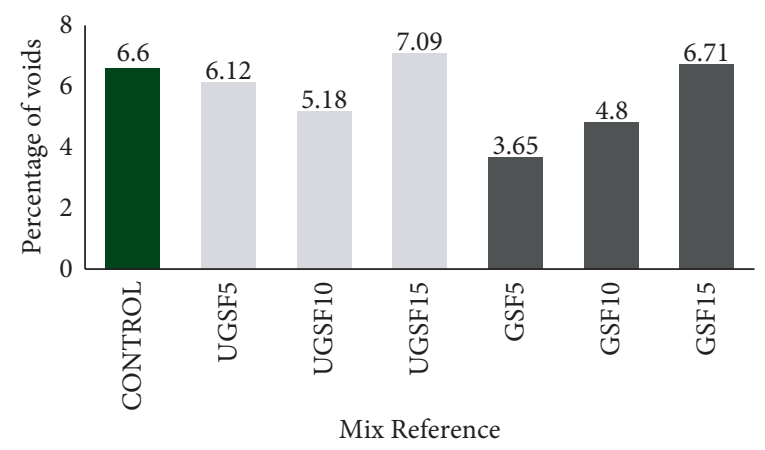

Figure 22: Porosity: SF.

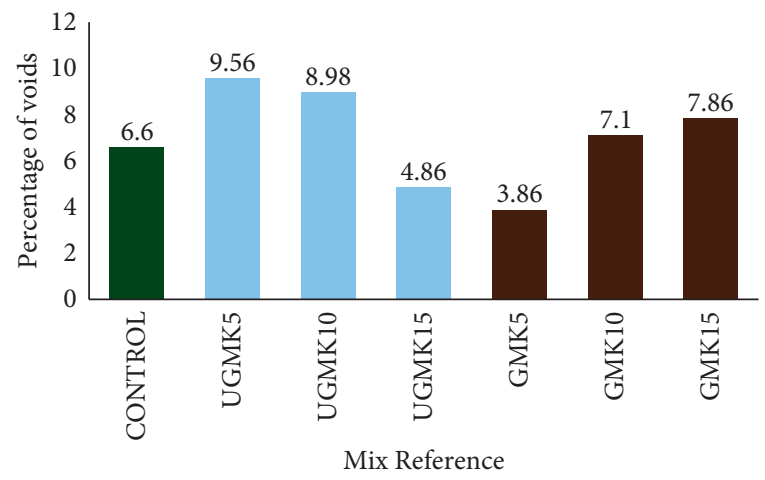

FIgURE 23: Porosity: MK.

admixture, the absorption values varied between $2.9 \%$ and $4.8 \%$; here, all the water absorption values are less than $1 \%$ indicating a low water absorption percentage. On referring Table 5 and Figures 13 and 14, it is understood that the sorptivity specimens with UGSF showed higher values than GSF, but the values are well within the limit. UGSF15 also has shown the higher sorption values which means it has let more water to pass inside making it weak. Among the GSFmixed specimens, GSF10 has shown a less sorptivity value of 0.002, and it indicates that the GSF10 has packed well the pores of concrete which would increase the strength and GSF has shown a higher sorption value, and higher sorption value indicates that the water permeation was more. GSF15 use with finer material in concrete did not improve the water 
permeation as a major number of finer particles have dissolved or might have been wasted in the mixing process as air dust. As the water absorption characteristics of GSF 5 were less compared to those of GSF10 and GSF 15, the sorption coefficient values of GSF 10 and GSF15 were very less among all SF-mixed specimens. But, as discussed earlier, the sorption values involve large decimal values and the rounded values are presented in Table 5. It is just an indication to identify whether the permeation is under control; moreover, use of finer materials requires more water as the specific surface is increased which will affect the strength of concrete, so on an overall observation, GSF 5 can be considered as an optimum mix among all.

\subsection{Water Absorption and Sorption Coefficient of MK-Blended} Binary Mix. Figure 15 illustrates the water absorption values of different specimens from which it is understood that the ultrafine ground particles are unable to fill the pores and less water absorption was shown by UGMK15 specimens.

It is reported by Khatib et al. [24] that when metakaolin was used as a mineral admixture in the normal state, the water absorption values ranged between $4.2 \%$ and $5.4 \%$. On comparing those with present experimental results, it was noted that water absorption values were less and the highest values are reported in UGMK and were found to be only $1.28 \%$ and $1.35 \%$. The details are illustrated in Figure 14 . From Table 5, it is clear MK-based specimens showed less sorption values irrespective of the nature whether unground and ground. The less sorption values indicate that the pores are properly packed. The less sorption values will lead to high strength, and it can be referred from the mechanical properties discussed by the same authors [13]. Much difference in sorption coefficient values was not identified among UGMK and GMK specimens. Though the sorption and water absorption characteristics are based on the masses of the specimens in water, the results are little contradictory as UGMK specimens show high water absorption than GMK and the difference was found to be less in sorption values. Sorption values use more decimal digits, and the difference can be noted when larger decimal digits were considered. But, it is clear that the effect of grinding has improved the water permeation resistance. Figures 16 and 17 show the sorption coefficient of UGMK- and GMK-based concrete specimens.

\subsection{Water Absorption and Sorption Coefficient of CP-Blended} Binary Mix. On observing the water absorption characteristics of the ceramic powder-mixed concrete specimen, it was found that CP15 has absorbed water less of about $0.88 \%$ than CP5 and CP10 for which the water absorption values were found to be $1.35 \%$ and $1.25 \%$, respectively. Figure 17 shows the percentage of water absorbed by CP-mixed specimens compared with control. The sorption values of the specimens cast with CP are shown in Figure 16, and from Table 5, it is evident that the difference between CP5 and $\mathrm{CP} 10$ sorption values is very less. On comparing this with the strength results of Karthikeyan and Dhinakaran [11], it is evident that CP15 has exhibited more strength of $58.8 \mathrm{MPa}$ than $\mathrm{CP} 5$ or $\mathrm{CP} 10$. CP is not finer than silica fume or MK, so its water absorption values are more than those of the specimens made with GSF, UGSF, GMK, or UGMK. But, among the ceramic-based concrete specimens, CP 15 has shown better water-resisting characteristics and lower sorption value which indicates that, with ceramic powder, a better resisting mix is possible with use of larger quantity of ceramic powder. Figures 18 and 19 show the percentage of water absorption and sorption values of $\mathrm{CP}$ with different replacement percentages compared with control.

4.5. Water Absorption and Sorption Coefficient of CSFBlended Mix. Among ternary blended mix, CSF15 has shown a less water absorption of $0.72 \%$ and a lower sorption coefficient of 0.074 making it better than the other ternary blended mixes CSF5 and CSF10 which have shown a water absorption of $3.33 \%$ and $1.18 \%$ and sorptivity values of 0.241 and 141. This improvement in the mixes compared with those made with cement and $\mathrm{CP}$ alone on reduced water absorption and lower sorption coefficient is due to the addition of $1 \%$ finer SF along with CP in all the mixes. The presence of cement, SF, and CP provided a densely packed mix filling up the pores, and the water permeation was controlled. Figures 20 and 21 illustrate these details. On comparing these results with the strength results of Karthikeyan and Dhinakaran [4], it can be seen that the trend observed in compressive strength and tensile strength is repeated as in the previous cases also, CSF15 performed better than CSF5 and CSF10.

4.6. Sorptivity: Overall View. According to Güneyisi et al. [2], the increase in SF and MK content resulted in lower sorptivity in concrete. A similar result was obtained in the present work also and was due to the modification of microstructure and secondary hydration. The pozzolanaic materials such as SF or MK have the tendency to improve the pore-filling capability by reactions with the calcium hydroxide evolved during hydration, thereby making the interfacial transition zone dense, and in addition to this, the ultrafine property has helped them to some extent in filling up the pores and increasing strength or water absorption characteristics. The CP-blended mixes are not expected to show high pozzolanic reactions, and the resistance to water absorption is mainly compared with that of those made with UGSF, GSF, UGMK, and GMK, but this can be rectified on using them with other finer materials such as SF in suitable proportion, and this resulted in a better sorption coefficient for the CP-mixed specimens as to the pores got filled effectively.

4.7. Void Percentage in SF-Blended Binary Mix and Ternary Mix. Figure 22 shows the voids percentage for various mixes. The porosity values of all the specimens mostly reflected the water absorption results and also helped to arrive at a proper justification for the water absorption values. Control concrete showed a void percentage of 6.6. Though the finer silica fume helps in filling the pores in concrete, 
sometimes, it may also get dissolved and get dispersed in the mix. This problem has occurred when the finer particles were added in large replacement levels such as 15\% for UGSF and GSF-mixed specimens; they were unable to fill the gap of cement left over and were unable to control the formation of pores and showed a higher porosity among GSF specimens. The SF particles either got dispersed or dissolved making the concrete vulnerable to air voids which convey that the addition of finer particles may not yield better results. Other SF-mixed specimens UGSF5, UGSF10, GSF5, and GSF10 have restricted the presence of air voids and protected the specimens from being affected with pores. The specimen made with UGSF in all combinations (5\%,10\%, and 15\%) showed only moderate porosity value making it a possible supplementary material for cement.

4.8. Porosity: Void Percentage in MK-Blended Binary Mix. MK-mixed specimens, though cannot fill the pores as SF fills because of their size being coarser than SF, have put up a decent effort in filling up the pores due to their ability to form additional calcium silicate gel during hydration. UGMK when added in lower quantity has not much effect in filling the pores, and the porosity values were more than those of the control specimens; on slowly increasing the replacement, the results turned to be good for UGMK, and the one with $15 \%$ replacement showed a better filling capacity with less porosity values than control. Ground MK specimens have shown porosity values which reflected the water absorption and compressive strength values. A much less value of $3.86 \%$ was seen for GMK5, and the values of other GMK specimens showed a gradual increase in porosity as the replacement levels were increased. The void percentage was nominal for GMK 5 and GMK 10 and was higher for GMK15. So, adding ultrafine particles more in the mix affected the specimen by making it more porous. So, GMK 5 and GMK 10 were found to be better with nominal void percentages. These details are illustrated in Figure 23.

\section{Conclusions}

The following were the conclusions obtained from the experiments conducted:

(1) Using ultrafine mineral admixtures made with conventional mineral admixtures such as SF and MK in more significant replacement levels affected the water permeation resistance as the specimens dragged more water into them due to an increased specific surface area.

(2) Considering the UGMK and GMK specimens, samples with less replacement of GMK showed better resistance to water permeation. The water absorption and porosity values gradually increased from GMK5 to GMK 15.

(3) On comparing all the tests, GMK5 showed better resistance to water and air void permeation.

(4) The sorption values of GSF5, GSF10, and GSF15 were minor. The water absorption and porosity characteristics gradually increased, with GSF5 possessing lower water absorption and void percentage and GSF15 having higher values.

(5) Though GSF10 and GSF15 possessed lower sorption values, the values increased as finer particles were added to the mix. The presence of more ultrafine particles increased the water requirement of the mix due to their increased specific surface area. So, GSF 5 is considered an optimum replacement level among the blends made with UGSF and GSF.

(6) Among the binary blended mixes, GSF5, GMK5, and CP15 are the identified optimum mixtures resisting water absorption and air voids.

(7) In the ternary blended mixes, CSF15 showed better permeation resistance characteristics with less sorption coefficient and low water absorption and is identified as the optimum mix in this category.

(8) Also, adding CP in a significantly less quantity of $5 \%$ or $10 \%$ in binary or ternary blended mixes was ineffective in improving the resistance to water permeation.

\section{Abbreviations}

OPC: Ordinary Portland cement

C: $\quad$ Control concrete

SF: $\quad$ Silica fume

UGSF: Unground silica fume

GSF: Ground silica fume

UGMK: Unground metakaolin

GMK: Ground metakaolin

CP: $\quad$ Ceramic powder

CSF: Silica fume blended with ceramic powder.

\section{Data Availability}

All data are included in the manuscript.

\section{Conflicts of Interest}

The authors declare no conflicts of interest.

\section{References}

[1] T. Gonen and S. Yazicioglu, "The influence of compaction pores on sorptivity and carbonation of concrete," Construction and Building Materials, vol. 21, no. 5, pp. 1040-1045, 2007.

[2] E. Güneyisi, K. Mermerdaş, and K. Mermerdas, "Strength deterioration of plain and metakaolin concretes in aggressive sulfate environments," Journal of Materials in Civil Engineering, vol. 22, no. 4, pp. 403-407, 2010.

[3] C. S. Poon, S. C. Kou, and L. Lam, "Compressive strength, chloride diffusivity and pore structure of high performance metakaolin and silica fume concrete," Construction and Building Materials, vol. 20, no. 10, pp. 858-865, 2006.

[4] B. Karthikeyan and G. Dhinakaran, "Strength and durability studies on high strength concrete using ceramic waste powder," Structural Engineering \& Mechanics, vol. 61, no. No.2, pp. 171-181, 2017. 
[5] B. Karthikeyan, R. Kathyayini, V. Aravindh kumar, V. Uthra, and S. Senthil Kumaran, "Effect of dumped iron ore tailing waste as fine aggregate with steel and basalt fibre in improving the performance of concrete," Materials Today Proceedings, vol. 46, pp. 7624-7632, 2021.

[6] B.-W. Jo, C.-H. kim, G.-h. Tae, and J.-B. Park, "Characteristics of cement mortar with nano-SiO2 particles," Construction and Building Materials, vol. 21, no. 6, pp. 1351-1355, 2007.

[7] F. Pacheco-Torgal, S. Miraldo, Y. Ding, and J. A. Labrincha, "Targeting HPC with the help of nanoparticles: an overview," Construction and Building Materials, vol. 38, pp. 365-370, 2013.

[8] N. Ali and S. Riahi, " $\mathrm{TiO}_{2}$ nanoparticles effects on physical, thermal and mechanical properties of self-compacting concrete with ground granulated blast furnace slag as binder," Energy and Buildings, vol. 43, pp. 995-1002, 2011.

[9] S. Riahi and A. Nazari, "RETRACTED: physical, mechanical and thermal properties of concrete in different curing media containing $\mathrm{ZnO} 2$ nanoparticles," Energy and Buildings, vol. 43, no. 8, pp. 1977-1984, 2011.

[10] N. Ali and S. Riahi, "The effects of $\mathrm{ZnO} 2$ nano-particles on split tensile strength of self-compacting concrete," Journal of Experimental Nanoscience, vol. 7, pp. 491-512, 2012.

[11] B. Karthikeyan and G. Dhinakaran, "Influence of ultrafine $\mathrm{TiO} 2$ and silica fume on performance of unreinforced and fiber reinforced concrete," Construction and Building Materials, vol. 161, pp. 570-576, 2018.

[12] B. Karthikeyan, A Subin, and T Muthulakshmi, "High strength concrete using Ultra-fine $\mathrm{TiO}_{2}$ and Basalt fiber- A study on Mechanical and Durability characteristics," The Romanian Journal of Materials, vol. 50, no. 1, pp. 51-58, 2020.

[13] B. Karthikeyan and G Dhinakaran, "Effect of ultra-fine $\mathrm{SiO}_{2}$ and metakaolin on high strength concrete in aggressive environment," Scientia Iranica, vol. 24, no. 1, pp. 1-10, 2017.

[14] B. Karthikeyan, N. Chidambaram, J. Srikanth, and G. Dhinakaran, "Mechanical properties and micro structure characteristics of ternary blended concrete with ceramic powder and $\mathrm{SiO}_{2}$," Asian Journal of Scientific Research, vol. 8, no. 3, pp. 291-303, 2015.

[15] J. Chai, K. Kiattikomol, V. Sata, and T. Leekeeratikul, "Use of ground coarse fly ash as a replacement of condensed silica fume in producing high-strength concrete," Cement and Concrete Research, vol. 34, pp. 549-555, 2004.

[16] B. Felekoğlu, S. Türkel, and H. Kalyoncu, "Optimization of fineness to maximize the strength activity of high-calcium ground fly ash-Portland cement composites," Construction and Building Materials, vol. 23, pp. 2053-2061, 2009.

[17] S. Teng, T. Y. D. Lim, and B. Sabet Divsholi, "Durability and mechanical properties of high strength concrete incorporating ultra fine Ground Granulated Blast-furnace Slag," Construction and Building Materials, vol. 40, pp. 875-881, 2013.

[18] L. Basheer, J. Kropp, and D. J. Cleland, "Assessment of the durability of concrete from its permeation properties: a review," Construction and Building Materials, vol. 15, no. 2-3, pp. 93-103, 2001.

[19] Q. Niu, N. Feng, J. Yang, and X. Zheng, "Effect of superfine slag powder on cement properties," Cement and Concrete Research, vol. 32, no. 4, pp. 615-621, 2002.

[20] ASTM150, Standard Specification for Portland Cement, ASTM International, West Conshohocken, PA, USA, 2006.

[21] ASTM C 1585-13, Standard Test Method for Measurement of Rate of Absorption of Water by Hydraulic-Cement Concretes, ASTM International, West Conshohocken, PA, USA, 2011.
[22] ASTM C 642-13, Standard Test Method for Density, Absorption, and Voids in Hardened Concrete, ASTM International, West Conshohocken, PA, USA, 2021.

[23] H. Abdul Razak, H. K. Chai, and H. S. Wong, "Near surface characteristics of concrete containing supplementary cementing materials," Cement and Concrete Composites, vol. 26, no. 7, pp. 883-889, 2004.

[24] J. M. Khatib, R. M. Clay, and R. M. Clay, "Absorption characteristics of metakaolin concrete," Cement and Concrete Research, vol. 34, no. 1, pp. 19-29, 2004.

[25] V. V Kumar and S. S Kumaran, "Friction material composite: types of brake friction material formulations and effects of various ingredients on brake performance-a review," Materials Research Express, vol. 6, 2019.

[26] S. Senthil Kumaran, S. Muthukumaran, D. Venkateswarlu, G. K. Balaji, and S. Vinodh, "Eco-friendly aspects associated with friction welding of tube-to-tube plate using an external tool process," International Journal of Sustainable Engineering, vol. 5, no. 2, pp. 120-127, 2012.

[27] S. Senthil Kumaran and A. Daniel Das, "Friction welding joints of SA 213 tube to SA 387 tube plate boiler grade materials by using clearance and interference fit method," Materials Today Proceedings, vol. 5, no. 2, pp. 8557-8566, 2018. 